This item was submitted to Loughborough's Research Repository by the author.

Items in Figshare are protected by copyright, with all rights reserved, unless otherwise indicated.

\title{
Challenges in implementation of a distributed and localised approach to food manufacturing
}

PLEASE CITE THE PUBLISHED VERSION

https://doi.org/10.18848/2160-1933/CGP/v08i03/1-14

\section{PUBLISHER}

Common Ground Research Networks @ Common Ground Research Networks, The Authors

\section{VERSION}

VoR (Version of Record)

\section{PUBLISHER STATEMENT}

This work is made available according to the conditions of the Creative Commons Attribution-NonCommercialNoDerivatives 4.0 International (CC BY-NC-ND 4.0) licence. Full details of this licence are available at: https://creativecommons.org/licenses/by-nc-nd/4.0/

\section{LICENCE}

CC BY-NC-ND 4.0

\section{REPOSITORY RECORD}

Gimenez-Escalante, Pedro, and Shahin Rahimifard. 2019. "Challenges in Implementation of a Distributed and Localised Approach to Food Manufacturing”. figshare. https://hdl.handle.net/2134/28445. 


\section{Food Studies}

An Interdisciplinary Journal

Challenges in Implementation of a Distributed and Localised Approach to Food Manufacturing 


\section{EDITOR}

Courtney Thomas, Virginia Polytechnic Institute and

State University, USA

HEAD OF JOURNAL PRODUCTION

McCall Macomber, Common Ground Research Networks, USA

\section{EDITORIAL ASSISTANT}

Hannah Werner, Common Ground Research Networks, USA

\section{ADVISORY BOARD}

The Food Studies Research Network recognizes the contribution of many in the evolution of the Research Network. The principal role of the Advisory Board has been, and is, to drive the overall intellectual direction of the Research Network. A full list of members can be found at http://food-studies.com/about/advisory-board.

\section{PEER REVIEW}

Articles published in Food Studies: An Interdisciplinary Journal are peer reviewed using a two-way anonymous peer review model. Reviewers are active participants of the Food Studies Research Network or a thematically related Research Network. The publisher, editors, reviewers, and authors all agree upon the following standards of expected ethical behavior, which are based on the Committee on Publication Ethics (COPE) Codes of Conduct and Best Practice Guidelines. More information can be found at:

\section{FOOD STUDIES:}

AN INTERDISCIPLINARY JOURNAL

http://food-studies.com

ISSN: 2160-1933 (Print)

ISSN: 2160-1941 (Online)

http://doi.org/10.18848/2160-1933/CGP (Journal)

First published by Common Ground Research Networks in 2018 University of Illinois Research Park

2001 South First Street, Suite 202

Champaign, IL 61820 USA

$\mathrm{Ph}:+1-217-328-0405$

http://cgnetworks.org

Food Studies: An Interdisciplinary Journal

is a peer-reviewed, scholarly journal.

\section{COPYRIGHT}

(C) 2018 (individual papers), the author(s)

(C) 2018 (selection and editorial matter),

Common Ground Research Networks

\section{(ㅇ)(1) $(5)$}

Some Rights Reserved

Public Licensed Material: Available under the terms and conditions of the Creative Commons Attribution-NonCommercial-NoDerivatives 4.0 International Public License (CC BY-NC-ND 4.0). The use of this material is permitted for non-commercial use provided the creator(s) and publisher receive attribution. No derivatives of this version are permitted. Official terms of this public license apply as indicated here: https://creativecommons.org/licenses/by-nc-nd/4.0/legalcode

\section{Crossref}

http://food-studies.com/journal/model.

\section{ARTICLE SUBMISSION}

Food Studies: An Interdisciplinary Journal publishes quarterly (March, June, September, December). To find out more about the submission process, please visit http://food-studies.com/journal/call-for-papers.

\section{ABSTRACTING AND INDEXING}

For a full list of databases in which this journal is indexed, please visit http://food-studies.com/journal.

\section{RESEARCH NETWORK MEMBERSHIP}

Authors in Food Studies: An Interdisciplinary Journal are members of the Food Studies Research Network or a thematically related Research Network. Members receive access to journal content. To find out more, visit http://food-studies.com/about/become-a-member.

\section{SUBSCRIPTIONS}

Food Studies: An Interdisciplinary Journal is available in electronic and print formats. Subscribe to gain access to content from the current year and the entire backlist. Contact us at support@cgnetworks.org.

\section{ORDERING}

Single articles and issues are available from the journal bookstore at http://cgscholar.com/bookstore.

\section{HYBRID OPEN ACCESS}

Food Studies: An Interdisciplinary Journal

is Hybrid Open Access, meaning authors can choose to make their articles open access. This allows their work to reach an even wider audience, broadening the dissemination of their research. To find out more, please visit http://food-studies.com/journal/hybrid-open-access.

\section{DISCLAIMER}

The authors, editors, and publisher will not accept any legal responsibility for any errors or omissions that may have been made in this publication. The publisher makes no warranty, express or implied, with respect to the material contained herein. 


\title{
Challenges in Implementation of a Distributed and Localised Approach to Food Manufacturing
}

\author{
Pedro Gimenez-Escalante, ${ }^{1}$ Loughborough University, UK \\ Shahin Rahimifard, Loughborough University, UK
}

\begin{abstract}
Existing large-scale centralised food production practices are often unsustainable due to requirements for significant transportation of both raw materials and finished products. These approaches also require substantial concentrated demands on energy and water. In addition, increasing amounts of food waste are being generated worldwide by manufacturers and retailers due to their dependence on unreliable demand forecasting methods as part of centralised production practices. Regulatory pressures and policy requirements as well as consumer demands for increased variety, improved traceability, and healthy diets are forcing manufacturers and retailers to reconsider their ingredient sourcing, production, storage, and distribution strategies. "Distributed and Localised Manufacturing" (DLM) aims to provide the food sector with capabilities to improve the efficiency of production systems, to optimise logistics operations across supply chains, and to extend the shelf life of products. However, to achieve these potential benefits, the implementation of DLM will involve many challenges that need to be carefully considered and addressed. This article explores these challenges and describes four specific implementation models to aid with the development of innovative and appropriate DLM structures for various food products.
\end{abstract}

Keywords: Distributed Localised Manufacturing, Food Supply Chains, Resource Efficiency

\section{Introduction}

$\mathrm{T}$

The long-term sustainability and efficiency of food manufacturing systems must improve to overcome upcoming challenges such as population growth, unpredictable markets, regulatory restrictions, and ever-changing consumer demand. There is a need for innovative production strategies that not only address the aforementioned problems that food manufacturers face on a daily basis, but also are able to adapt to future challenges yet to be identified. Furthermore, these new production strategies should offer the ability to customise food products, minimise waste generation, and increase product shelf life to boost food sector performance (Notarnicola et al. 2017).

Solutions to identifying optimum facility location, production allocation and vehicle routing issues are fundamental to ensuring a more sustainable future food supply (Manzini et al. 2013). Rising distribution costs and supply chain restrictions linked to globalised food systems are increasing complexity within the food industry resulting in additional management intricacies for businesses aiming to remain competitive and profitable ( $\mathrm{Li}$ et al. 2014). Additionally, manufacturers are demanding alternative production models to effectively implement innovative manufacturing processes and technologies such as additive manufacturing with promising potential to beneficiate the sector (Gao et al. 2015).

In this context, the concept of a distributed approach to food manufacturing has recently benefited from a rapid growth of principles and associated technologies. This article provides an overview of the concept of "Distributed Localised Manufacturing" (DLM) together with some of the key drivers and challenges that food businesses might face in future applications. In addition, the article presents four potential DLM implementation models and exemplifies how DLM could be used in practice for the production of bread and tomato paste.

\footnotetext{
${ }^{1}$ Corresponding Author: Pedro Gimenez-Escalante, Centre for SMART, Wolfson School, Loughborough University, Loughborough, Leicestershire, LE11 3TU, United Kingdom. email: p.gimenez@loughborough.ac.uk
}

Food Studies: An Interdisciplinary Journal

Volume 8, Issue 3, 2018, http://food-studies.com

(C) Common Ground Research Networks, Pedro Gimenez-Escalante,

Shahin Rahimifard, Some Rights Reserved, (CC BY-NC-ND 4.0).

Permissions: support@cgnetworks.org

ISSN: 2160-1933 (Print) ISSN: 2160-1941 (Online)

http://doi.org/10.18848/2160-1933/CGP/v08i03/1-14 (Article) 


\section{Global Food Manufacturing}

Food manufacturing is one of the biggest and most vital economic sectors worldwide due to its strategic role in ensuring the provision of daily food to the population. This includes a network of organisations that manufacture, process, and transform raw materials as well as partially processed food products sourced from primary producing activities (e.g., agriculture or fishing; Manzini et al. 2013). During the last few decades, the strategic approach toward increasing productivity and profitability of key actors in the food supply chain has been to scale up their production operations to increase their profits through economies of scale (Chisholm 1992). Today, multi-national food corporations often own fewer large-scale centralised sites that source raw materials and ingredients globally and then distribute food products to an increasing number of consumers who, in many cases, are located far from the factory gates (Henderson et al. 2000). This strategy has enabled manufacturing businesses to increase their profits by, for example, reducing the overhead costs per product or by minimising operations management costs (O'Reilly et al. 2015).

This trend, although highly profitable, is increasing the complexities associated with ordinary manufacturing operations such as accessing vital resources, ensuring product freshness, or being efficient in managing the stocks of ingredients and raw materials (Mahalik el al. 2010). Moreover, the increase in transport needs due to the internationalisation of supply chains is rising operational costs and emissions, greatly impacting manufacturing decisions pressured by sustainability requirements such as the fulfilment of carbon emissions targets (Del Borghi et al. 2014). Although numerous technological advances have supported the management and operation of these complex production systems and their associated supply chains, these are becoming less effective, highlighting the need for alternative approaches (Trienekens et al. 2012).

The food sector is submerged in a continuous improvement and adaptation cycle to make it capable of fulfilling changing consumer needs and demands (Lang 1999). Food manufacturing has historically pursued improved flexibility to react faster and better to market changes and therefore obtain larger benefits, which are the vital factor for business success in highly competitive markets. Rising demand for food products due to circumstances such as world population growth and dietary changes in conjunction with resource scarcity and ingredient complexity is now forcing the industry to innovate and utilise novel technologies and strategies (Valin et al. 2014; Kumar et al. 2016).

Future innovations in food manufacturing are expected to be based on the capabilities of all the agents involved in the provision of food. This includes agriculture, the manufacturing industry, and retailers (Sundbo 2016). These transformations are expected to generate unforeseen challenges that will necessitate solutions that can drive the food sector toward a more sustainable future.

\section{Distributed Manufacturing}

Distributed Manufacturing (DM) represents an alternative strategy that has the potential to increase the sustainability of future food production. This concept has been identified as the next evolution for manufacturing worldwide and is an emerging research field with the potential to address many existing manufacturing systems challenges (Moreno et al. 2017). It has been defined as a manufacturing strategy that encompasses numerous mutually dependent autonomous agents within collaborative production networks that are geographically dispersed and can operate independent of each other (Rauch et al. 2016).

DM has also been characterised as a means toward greater product customisation, which provides advantages derived from keeping manufacturing closer to market with better understanding of customer requirements (Devor et al. 2012). This strategy can generate 
numerous benefits such as reductions in logistics costs and emissions burdens and a better distribution of wealth. This could ultimately reduce the time from manufacturing to final consumption, which would positively influence production of highly perishable food products with short shelf life (Aramyan et al. 2007).

\section{Localised Manufacturing}

Localised Manufacturing (LM) is a concept closely related to DM as an alternative to globalised large-scale production. This innovative manufacturing strategy seeks the utilisation of "local" suppliers and local distribution of the finished products. LM systems have been characterised as being of smaller scale than traditional centralised structures, benefiting from faster response times to demand changes and enabling greater product personalisation (Forney et al. 2014).

One of the most crucial factors when considering the localisation of manufacturing is to define its scope. It has been identified that in order to be a viable option, the area under the influence of LM would need to be able to at least have the capabilities to supply raw materials and have the corresponding demand for the products ( $\mathrm{Wu}$ et al. 2016). Even though LM might incur a number of challenges for the food industry such as limited choices in terms of accessible ingredients, it must be noted that trends such as cyber infrastructure, the emergence of miniaturization technologies, and innovative processing technologies can address such potential limitations (Ford et al. 2015).

LM presents numerous potential opportunities and benefits that are expected to increase the sustainability of future food production. The utilisation of local supply chains could create closer relationships among all the actors involved in food production. Therefore, this supports more sustainable business practices such as waste reduction, support of local economy, and improvement of the resilience of food supply chains (Cowell et al. 2003; Holt et al. 2007).

\section{Modern Drivers and Challenges for DLM}

DLM can be broadly defined as a decentralised and closer to consumer production network, which provides increased flexibility and faster response to market needs. It functions based on a shorter supply chain aiming to support local economies and to ultimately increase long term sustainability of manufacturing businesses. This strategy not only aims to change the location, but also the way materials are sourced to provide a meaningful reduction in logistics costs and emissions derived from manufacturing, supply, and distribution operations (see Figure 1). 


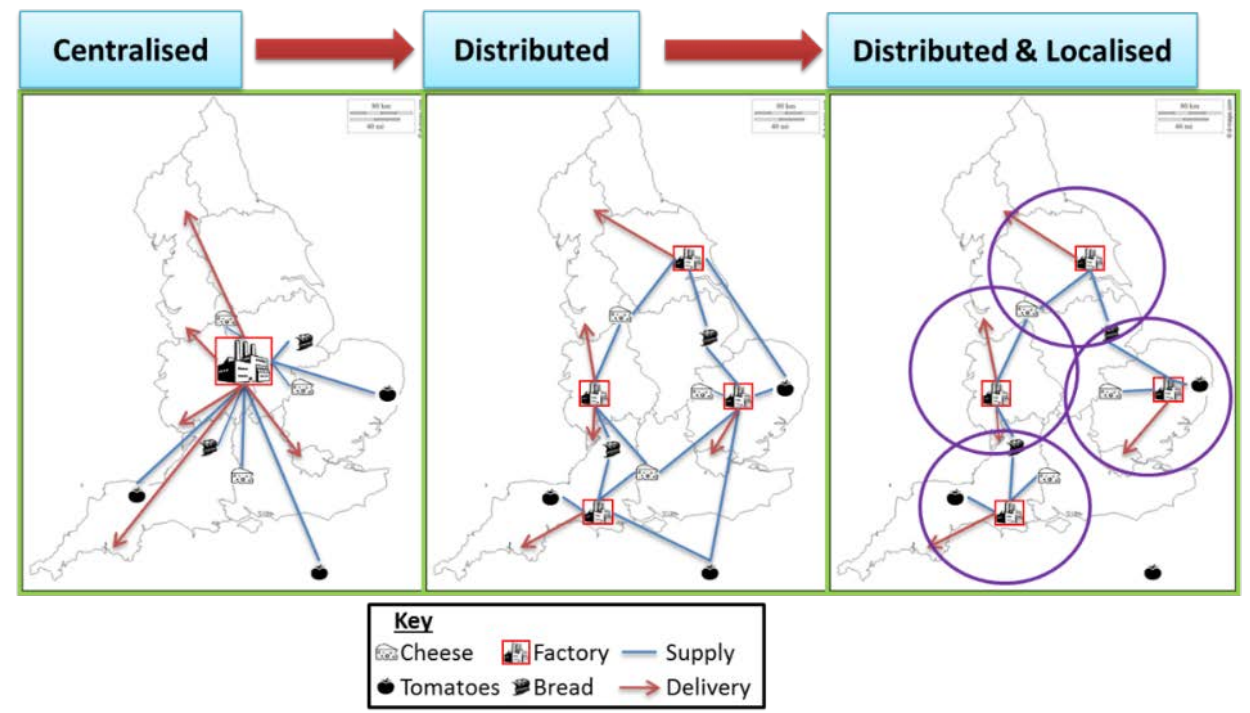

Figure 1: Distributed Localised Transition Rahimifard et al. 2017

To gain advantages from DLM and to stimulate its utilisation by food businesses, it is important to identify how advantages can be obtained and from where they are expected to emerge. A DLM approach can drive a change in the food industry towards more sustainable systems by not only minimising environmental impacts from supply chain operations, but also by impacting society through major shifts in production patterns. In addition, numerous economic benefits are expected to be obtained not only from the creation of new sources of income, but also from the reduction of costs and waste produced by large-scale centralised systems. Some of the most important drivers for the implementation of DLM by food manufacturers include:

- Optimised use of materials and resources: DLM can optimise ingredients and other resources sourcing practices via the minimisation of distances between actors (therefore lowering food miles) and reduce the negative effects of large scale food production such as the loss of arable land and depletion of natural resources (e.g., water).

- Customisation and personalisation of foods: DLM could minimise the complexities derived from the need to address the increasing shifts in consumer demand for highly customised or personalised products due to changes in diets and nutritional needs (e.g., due to aging population).

- Safety and traceability of products and ingredients: DLM could facilitate easier and simpler traceability of ingredients and products. Food safety, which has always been a major concern in the sector, can be improved by providing greater visibility and transparency not associated with complex globalised large-scale systems.

- Alternative demand management: DLM could support a more efficient food provision strategy for growing populations due to the increased production flexibility and the potential reduction in the dependence on forecasting approaches to fulfil market demand. 
However, it should be noted that the potential implementation of DLM by food businesses is expected to yield numerous challenges throughout the development stages. Organisations willing to follow this strategy need insight into predicted benefits before they commit to such a fundamental change in their structures and operational practices. Therefore, the early identification of potential barriers will greatly support the adoption of the distributed localised strategy. A number of relevant challenges for DLM adoption under the headings of product, process and system challenges are depicted in Figure 2 and are briefly described in the following sections.

\section{Product Related Challenges}

Food product attributes and characteristics (e.g., ingredients, shelf life, demand volatility, etc.) significantly influence the successful implementation of the DLM strategy. Considering that the current product development processes are set up mainly to support globalised food supply chains, it is expected that significant adaptations will be required for the provision of similar product ranges in localised systems. Furthermore, it will be vital to understand and decide which products can be produced based on a DLM approach to assure businesses of the long-term profitability.

On the other hand, maintaining a constant product quality could be challenging because increasing the number of facilities would demand greater efforts to ensure the fulfilment of quality parameters. Compared to single large-scale product systems that follow very structured and standardised quality assurance methods, DLM actors could require innovative strategies across facilities to generate robust quality controls. Additionally, the way products are designed and developed might need to be adapted considering that in some cases local manufacturers might have limited choices in terms of ingredients or technologies that they can utilise to prepare their products.

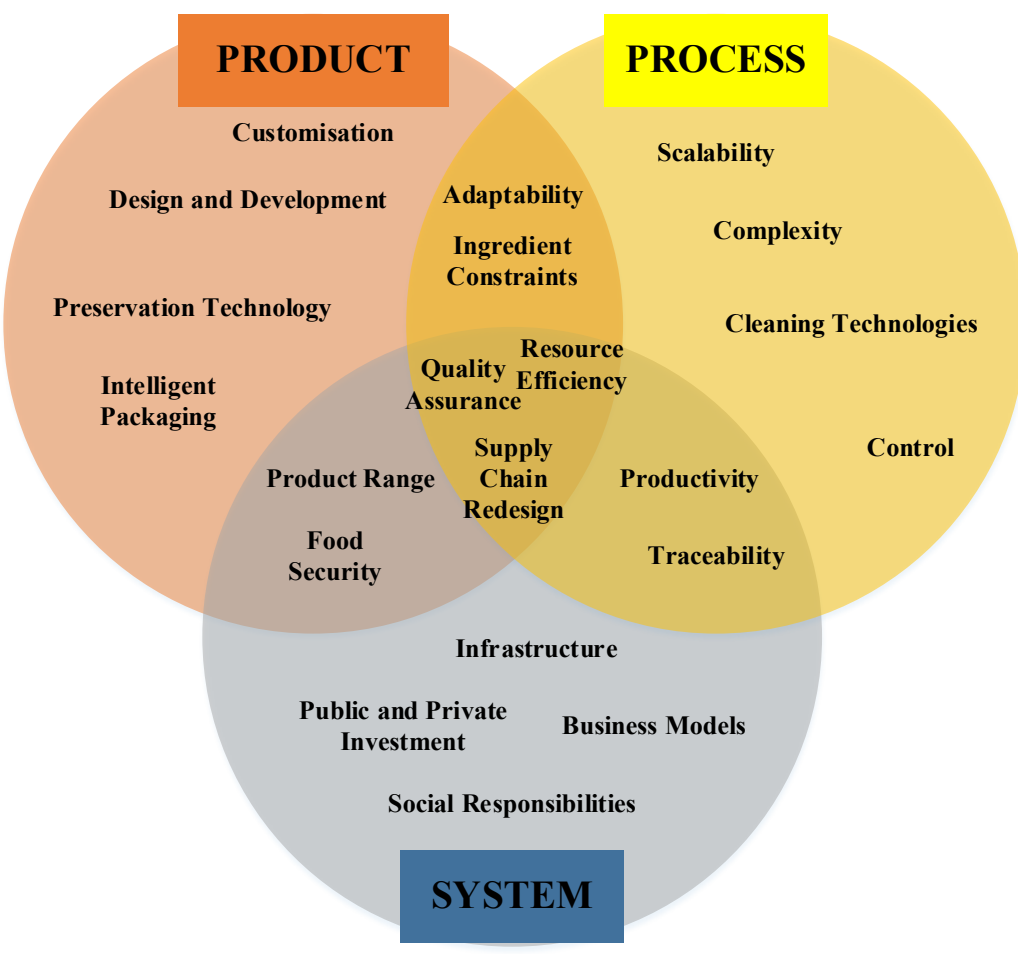

Figure 2: Product, Process, and System Challenges for DLM Implementation Gimenez-Escalante and Rahimifard 2017 


\section{Process Related Challenges}

Food processing technologies represent another area that will require fundamental adaptations to support DLM. Processing challenges include factors such as ensuring similar productivity to the larger-scale processes. DLM might challenge process flexibility and scalability to produce varying production batches required by localised markets.

Moreover, differences in the uniformity of locally produced raw materials - compared to ingredients used in large-scale production - could represent a very difficult challenge for future food processing technologies. Another important factor to consider is the potential need for alternative cleaning technologies that can efficiently work in smaller manufacturing facilities. An uncompromising approach to cleanliness of equipment to ensure food safety is one of the major challenges of food production. It will undoubtedly impact the feasibility of DLM and must be carefully considered in distributed manufacturing applications to ensure continuous safety of the products.

\section{System Related Challenges}

System level considerations epitomise the strategic tier, and they are essential for the optimum development of DLM. Future challenges in this category include fundamental aspects such as readiness and adaptability level of infrastructures to support innovative logistics and production strategies and accuracy and reliability of traceability procedures. Recent events in the EU with respect to a lack of knowledge or information about certain ingredients, product origins, or contents have shown the urgent necessity to develop precise traceability tools to reduce health risks.

Furthermore, there will be direct economic investment challenges for businesses aiming to benefit from the opportunities that DLM can offer to improve food manufacturing sustainability. The radical shifts in location, processing technologies, and capabilities, together with the predicted need for distributed workforce availability, will challenge organisations not only regarding strategic planning, but also in implementation and exploitation of these systems.

One key challenge at the system level is the need to redesign supply chains to enable a smooth transition toward DLM. Local suppliers might require innovative transportation routes in addition to alternative ingredient sources to ensure distributed food provision. This is expected to be one of the most important enablers that will support DLM utilisation in future food systems.

\section{Implementation Models for Distributed Localised Manufacturing of Food}

There are numerous considerations and needs that must be fulfilled for DLM strategies to be successfully implemented into food production. Fundamental considerations are the range of production processes undertaken based on a distributed method and/or at a local level and the identity of the actor in the supply chain that will carry out these processes. Four implementation models are proposed, which are expected to be applicable to different products and business scenarios, as illustrated in Figure 3 and described below. 


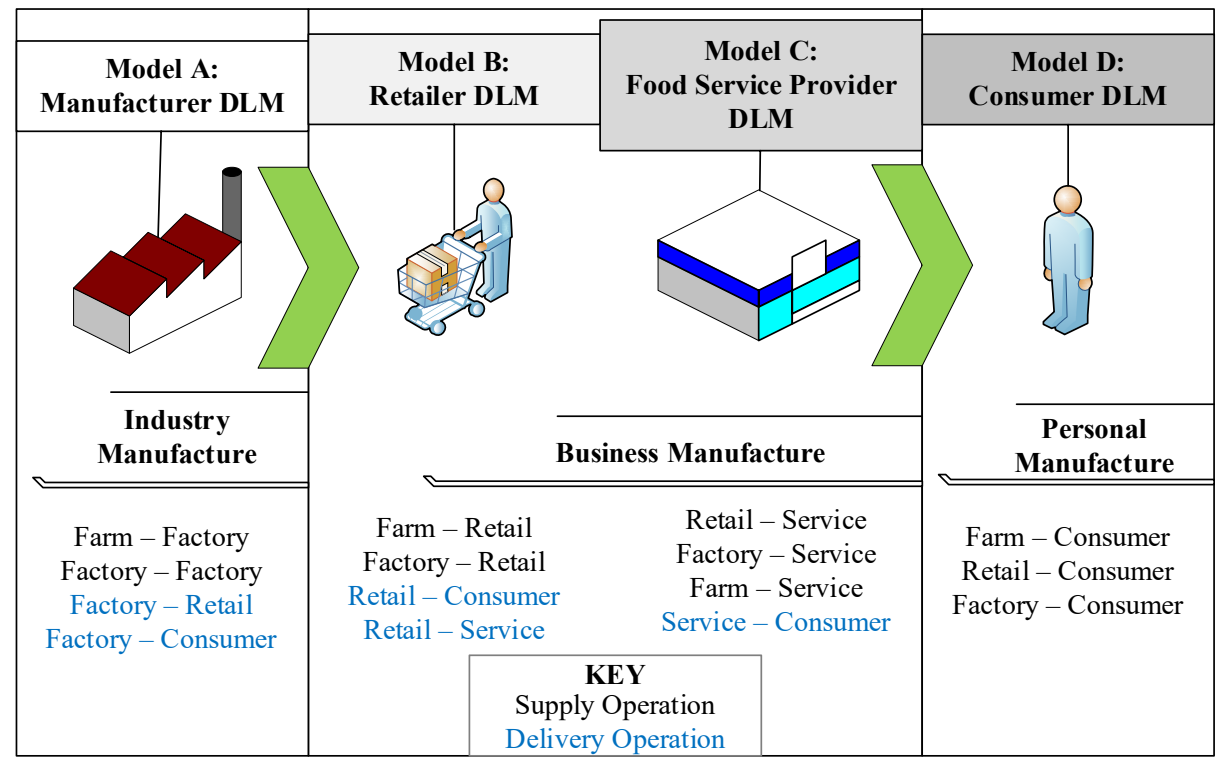

Figure 3: DLM Implementation Models

Gimenez-Escalante and Rahimifard 2017

\section{Model A: DLM by Manufacturer}

The main characteristic of this model is the generation of networks of independent manufacturing facilities capable of producing final products ready for consumption. This production structure can potentially be created based on similar processes and operations of current large-scale centralised systems but on a much smaller scale. However, it is envisaged that this model will require several enabling capabilities such as efficient small-scale technologies (e.g., microwaves and microfluidics), local access to ingredients, and an available skilled workforce to ensure the successful delivery of food products in potentially more constrained local environments. These manufacturing constraints could emerge due to more "limited" infrastructures resulting from smaller areas of supply and distribution at the local level compared to globalised manufacturing systems. The difference between the proposed model and existing centralised systems is a proportional reduction in facility size, which is linked to more regional geographical distribution that can ensure the same level of supply while achieving a more sustainable use of resources to manufacture food.

\section{Model B: DLM by Retailer}

This implementation model aims to enable the manufacturing or finalisation of products at the retail stage in the supply chain. Retailers would serve as distributed manufacturers being supplied with raw ingredients or semi-processed items by ingredient producers or primary processors. The last few processing steps would then be carried out at the retailer facility. This DLM approach would provide several benefits in terms of shelf life and freshness of products to consumers. It could also enable a "make-to-order" style of demand management in the food sector, reducing wastage and generating the opportunity to provide more customisable products to consumers. Some existing cases such as the increase of in-store bakeries or ready-meals kitchens have shown the potential of this type of approach, which could be optimised and extrapolated to other food items. 


\section{Model C: DLM by Food Service Provider}

This implementation model relies on specific service providers to improve the sustainability of the food sector. Food services could become "last mile processors," enabling a distributed supply of higher quality and fresher products. Manufacturers and raw-material providers would become less constrained by consumer demand for customised products. The increasing demand for ready meals and food-to-go provides numerous opportunities for this strategic approach. Changing the way food services source and process ingredients and enhancing their capabilities to produce suitable sustainable food products can provide several benefits such as significant food waste reductions and the stimulation of growth and development in local economies.

In this DLM implementation model, manufacturers and retailers would get involved in supplying semi-processed ingredients to the service provider facilities. Services would have the same role that they currently fill in society: providing consumers with food near their homes. However, in this more localised approach, manufacturers and retailers will improve the sustainability of the sector rather than focusing purely on profit.

\section{Model D: DLM by Consumer}

The consumer model seeks to create supply networks that minimally prepare or process raw materials into ingredients that are supplied to consumers to assemble and create final food products at the point of consumption. Manufacturers and retailers would act as parts/ingredients/partially processed items suppliers, reducing their environmental impact (e.g., by minimising the need for resources during production or by reducing the energy utilisation for cold storage and transportation). Highly perishable ingredients could potentially be sourced locally by retailers, while longer shelf life ingredients could be manufactured in a distributed way and then supplied to consumers or to retailers depending on preference.

This model can be referred to as "personal manufacture," which would empower consumers to take on the role of "manufacturers." This would enable them to meet their specific needs in the best conceivable way. For example, this model could be applied to the provision of sustainable and healthy food for people with non-communicable diseases (e.g., diabetes and cardiovascular).

\section{Comparative Analysis of DLM Implementation Models}

Considering the above descriptions of the proposed models for DLM, it is evident that each model will be suitable for certain products, business scenarios, and consumption patterns. Figure 4 illustrates the characteristics that each of the models present from two different perspectives: Industrial and Technological. This initial assessment of the models highlights the most important characteristics, such as manufacturing flexibility or industrial lead time to consumption, that need to be considered when assessing the suitability of these models for a specific application. 


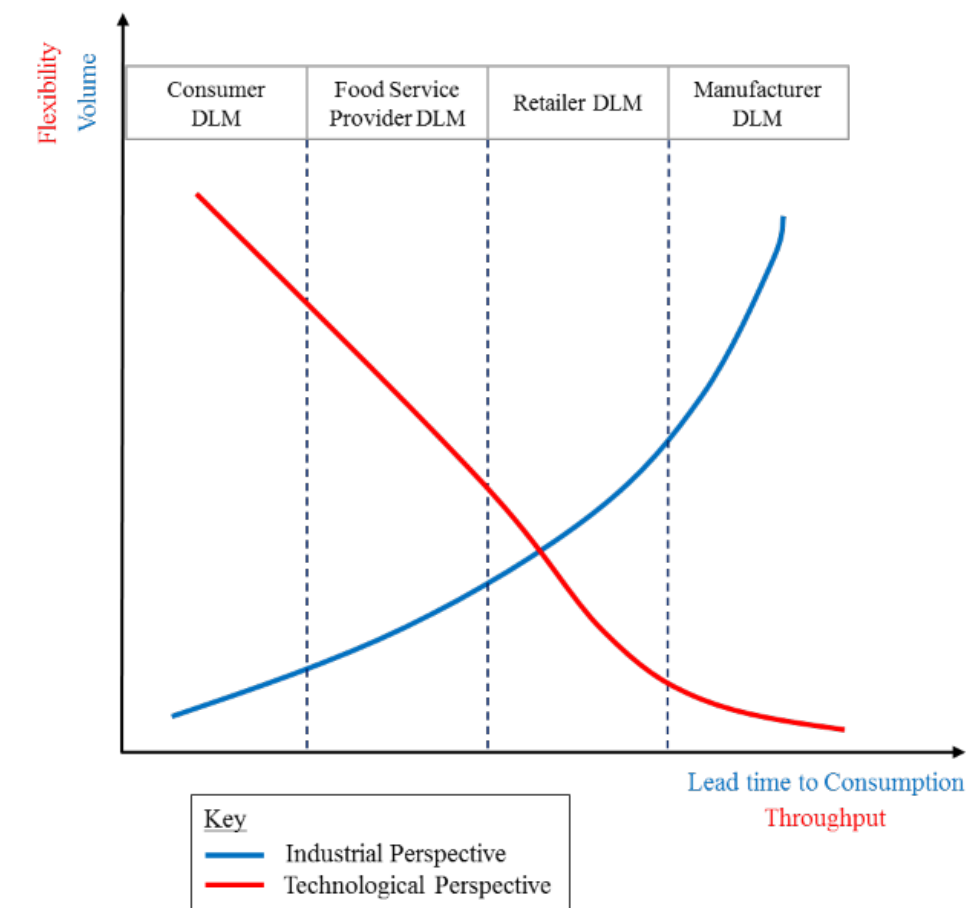

Figure 4: Comparative Models Standpoint from Industrial and Technological Perspectives Gimenez-Escalante and Rahimifard 2017

\section{DLM in Practice}

Specific food product attributes are likely to significantly influence the selection of suitable DLM implementation models. Case-by-case consideration is required to comprehend the extent of potential benefits and challenges when a specific model is utilised in the production of different food products. The wide range of product attributes that might influence this decision may well include factors such as the volume, variety, and customisation level of the products being manufactured; the need for shelf life extension through different preservation technologies; or potential constraints in local availability of supply, including quantity, quality, or high perishability of ingredients. For instance, previous studies on the redistribution of the manufacture of two distinctly different food products, bread and tomato paste, considered several of these potential issues (Cotee 2016; LNN Business Feasibility Project 2016).

In the case of bread, regarding production requirements, the study considered the relocalisation of milling (transformation of wheat and other cereals into flour) and baking (ingredients mixing and dough cooking) processes in the UK (Cotee 2016). Concerning milling, the study concluded that there are not many redistribution opportunities due to the extended standardisation of a low value-added product linked to a low demand for specialist flours. Besides, it was pointed out that the UK retail distribution system represents an important barrier to the implementation of regional or local milling facilities, and the study highlighted the uneconomic and time-consuming nature of household milling. On the other hand, the study identified the potential for re-localising baking operations through the creation of innovative products. Novel products could bring back artisan practices enabling simultaneously a reduction in manufacturing volumes and an increase in flexibility. Through these two benefits and potential quality improvements, predicted price increases that could be expected from a distributed approach would be potentially justified. 
In a related study analysing business model issues regarding the localisation of bread production, it was concluded that although a complete local redesign for the supply might not be realistic, there are several opportunities to distribute or partially localise different operations, creating alternative re-localised models (LNN Business Feasibility Project 2016). Alternative business models could be implemented in parallel to the centralised and global supply chain dependent traditional strategies. This study established that potentially shortened supply chains could be designed to enable the manufacturing of bread closer to the consumer, depending on the degree of localisation.

Concurrently, the studies respectively analysed the potential to locally manufacture tomato paste in the UK. From a production perspective, it was concluded that it would not be socially or economically sustainable to manufacture this product in the UK. The main drawback identified was the predicted challenge in obtaining a sufficient local supply of tomatoes. However, the study considered re-localisation in West African countries and concluded that in those cases in which primary supply is not a limiting factor, there could be potential to generate small scale production units, reducing the dependency on refrigerated transport and reliable infrastructures. On the other hand, regarding potential business issues, it was pointed out that due to the necessity of locating tomato paste facilities near tomato growing areas and considering UK climate limited agricultural production of tomatoes, innovative business models could not easily support the relocalisation of this specific product.

The resulting data from these studies clearly indicates that due to sector-specific increasing requirements for customisation, growing consumer demand for high quality products, and need for optimum usage of shelf life, Models B, C, and D present a higher level of applicability for bread baking, whereas the milling process could potentially benefit from Model A. Conversely, due to constraints in localised availability of supply in the UK, higher energy demand for processing, and complexity of processing operations, the most feasible approach for tomato paste manufacturing would be Model A. Further key favourable and challenging points for the implementation of the models for each product are summarised in Table 1. 
Table 1: Comparative Facts for Implementing DLM Models in Bread and Tomato Manufacturing

\begin{tabular}{|c|c|c|}
\hline & Bread & Tomato Paste \\
\hline Model A & 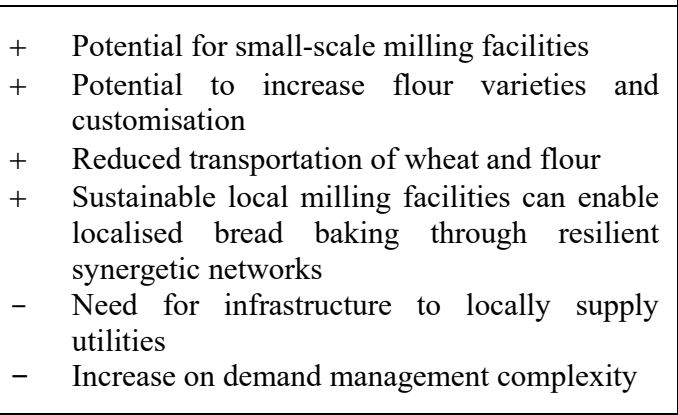 & $\begin{array}{l}+\quad \begin{array}{l}\text { Reduction in resource intensity } \\
\text { from large scale facilities }\end{array} \\
+\quad \begin{array}{l}\text { Potential to minimise number } \\
\text { of supply chain actors }\end{array} \\
+\quad \begin{array}{l}\text { Development of novel local } \\
\text { economies }\end{array} \\
+\quad \begin{array}{l}\text { Reductions in waste from farm } \\
\text { to factory }\end{array} \\
+\quad \begin{array}{l}\text { Increased batch size flexibility } \\
-\quad \begin{array}{l}\text { Climate constrained ingredient } \\
\text { availability }\end{array}\end{array} \\
\end{array}$ \\
\hline Model B & $\begin{array}{ll}+ & \begin{array}{l}\text { Bread make-to-order to reduce waste from } \\
\text { overproduction due to inefficient forecasting }\end{array} \\
+ & \text { Product freshness optimisation } \\
+ & \text { Potential to personalise bread recipe in store } \\
+ & \text { Dough baking or bread made from scratch } \\
+ & \text { Retail network of facilities could support the } \\
& \text { re-localisation of bread baking } \\
- & \text { Space demand in retail stores } \\
- & \text { Need for skilled retail labour } \\
- & \text { Challenging customer orders handling } \\
\end{array}$ & $\begin{array}{ll}\text { - } & \text { Long shelf life product } \\
\text { - } & \text { Complex product processing for } \\
& \text { retailer shop floor adoption } \\
- & \text { Long processing time }\end{array}$ \\
\hline Model C & 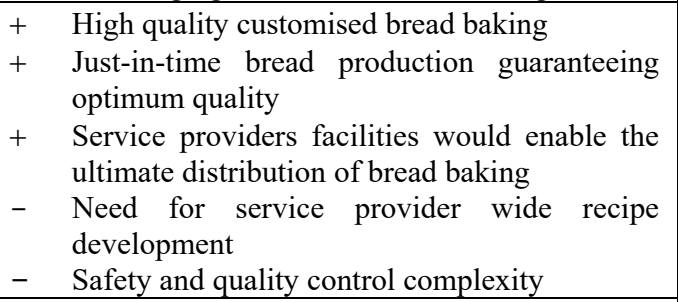 & $\begin{array}{l}\text { - Fresh ingredients are desired } \\
\text { for quality } \\
\text { - Paste production by service } \\
\text { providers would not be } \\
\text { economically beneficial } \\
\text { - Complex processing for most } \\
\text { service providers }\end{array}$ \\
\hline Model D & $\begin{array}{ll}+\quad \text { Minimisation of supply chain waste } \\
+\quad \begin{array}{l}\text { Reduction of potential quality and safety } \\
\text { issues derived from large-scale facilities }\end{array} \\
+\quad \begin{array}{l}\text { Increased sustainability from transporting raw } \\
\text { ingredients due to product weight ratio }\end{array} \\
-\quad \text { Need for consumer willingness to bake } \\
-\quad \text { Baking or cooking skills requirements }\end{array}$ & 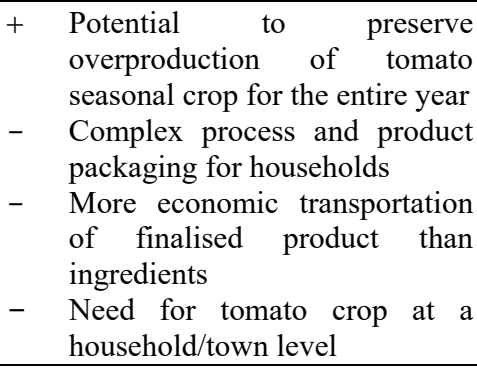 \\
\hline
\end{tabular}

Gimenez-Escalante and Rahimifard 2017

The specifics of the defined DLM models in conjunction with bespoke product attributes could be used to select the most appropriate model for a particular sector. Future research is focused on the development of a multi-criteria decision support method for assessing the implementation of the presented DLM models for the full range of products manufactured by food businesses.

\section{Conclusion}

The contemporary challenges faced by global food supply chains associated with redundant transportation between non-value adding actors, raw materials, and food products wasted before reaching consumers and the burdening need for more resilient and sustainable alternatives clearly point toward the need for DLM in future food production. The identified challenges should be carefully considered in future decision-making regarding the implementation of DLM. Only then 
will food organisations be capable of truly benefiting from the strategic utilisation of this approach, which is expected to not only increase the overall sustainability of the sector, but also to assist organisations with future continuous growth.

This article presented four implementation models to support the transition from traditional centralised large-scale food manufacturing to distributed and localised strategies. Each of these could provide advantages and benefits to food businesses and present specific intricacies for fruitful implementation. The proposed models could support the food industry by not only optimising resource utilisation and generating innovative approaches toward supply and distribution, but also by providing competitive advantages to fulfil rapidly changing consumer needs (e.g., consumers with restricted choices, growing demand for personalised diets).

The characteristics of food products must be carefully assessed against specific DLM criteria to ensure the generation of benefits when shifting from centralised production toward distributed and localised strategies. Furthermore, there is a need to understand and define some of the key attributes that could help identify how, where, and when DLM could potentially be implemented. Consequently, future research focuses on the development of a structured and formal assessment method that can support the selection of the best products, processes, and systems for categorical DLM implementation by manufacturers seeking to improve their business sustainability.

\section{Acknowledgement}

This work was supported by the Engineering and Physical Sciences Research Council [grant number EP/K030957/1], the EPSRC Centre for Innovative Manufacturing in Food.

\section{REFERENCES}

Aramyan, Lusine H., Alfons G. J. M. Oude Lansink, Jack G. A. J. van der Vorst, and Olaf van Kooten. 2007. "Performance Measurement in Agri-food Supply Chains: A Case Study." Supply Chain Management 12 (4): 304-15. https://doi.org/10.1108/13598540710759826.

Chisholm, Michael. 1992. "Britain, the European Community, and the Centralization of Production-Theory and Evidence, Freight Movements." Environment and Planning A 24 (4): 551-70. https://doi.org/10.1068/a240551.

Cottee, Julian. 2016. LNN Food Feasibility Project Final Report. Oxford: Environmental Change Institute, University of Oxford. http://localnexus.org/feasibility-projects/food -feasibility-project/.

Cowell, Sarah J., and Stuart Parkinson. 2003. "Localisation of UK Food Production: An Analysis Using Land Area and Energy as Indicators." Agriculture, Ecosystems \& Environment 94 (2): 221-36. https://doi.org/10.1016/S0167-8809(02)00024-5.

Del Borghi, Adriana, Michaela Gallo, Carlo Strazza, and Maria Del Borghi. 2014. "An Evaluation of Environmental Sustainability in the Food Industry through Life Cycle Assessment: The Case Study of Tomato Products Supply Chain." Journal of Cleaner Production 78 (1): 121-30. https://doi.org/10.1016/j.jclepro.2014.04.083.

DeVor, R. E., S. G. Kapoor, J. Cao, and K. F. Ehmann. 2012. "Transforming the Landscape of Manufacturing: Distributed Manufacturing Based on Desktop Manufacturing (DM)2." Journal of Manufacturing Science and Engineering 134 (4): 041004-041004-11. http://dx.doi.org/10.1115/1.4006095.

Ford, Simon J., Ursula Rauschecker, and Nikoletta Athanassopoulou. 2015. "Future Challenges for Multi-Site Manufacturing System of Systems." SSRN, February 11. http://dx.doi.org/10.2139/ssrn.2563521. 
Forney, Jeremie, and Isabel Häberli. 2014. "Is 'Local' Enough? New Localised Food Networks in the Swiss Dairy Industry." Paper presented at the 11th European IFSA Symposium, Berlin, Germany, April 1-4, 2014.

Gao, Wei, Yunbo Zhang, Devarajan Ramanujan, Karthik Ramani, Yong Chen, Christopher B. Williams, Charlie C. L. Wang, Yung C. Shin, Song Zang, and Pablo D. Zavattieri. 2015. "The Status, Challenges, and Future of Additive Manufacturing in Engineering." Computer-Aided Design 69: 65-89. https://doi.org/10.1016/j.cad.2015.04.001.

Henderson, Jason R., and Kevin T. McNamara. 2000. "The Location of Food Manufacturing Plant Investments in Corn Belt Counties." Journal of Agricultural and Resource Economics 25 (2): 680-97. http://www.jstor.org/stable/40987084.

Holt, Georgina, and Virginie Amilien. 2007. "Introduction: From Local Food to Localised Food." Anthropology of Food S2. http://aof.revues.org/405.

Kumar, Mukesh, Gary Grahan, Patrick Hennelly, and Jagjit Srai. 2016. "How Will Smart City Production Systems Transform Supply Chain Design: A Product-level Investigation." International Journal of Production Research 54 (23): 7181-92. http://dx.doi.org/10.1080/00207543.2016.1198057.

Lang, Tim. 1999. "The Complexities of Globalization: The UK as a Case Study of Tensions within the Food System and the Challenge to Food Policy." Agriculture and Human Values 16 (2): 169-85. https://doi.org/10.1023/A:1007542605470.

Li, Dong, Xiaojun Wang, Hing Kai Chan, and Riccardo Manzini. 2014. "Sustainable Food Supply Chain Management.” International Journal of Production Economics 152: 1-8. https://doi.org/10.1016/j.ijpe.2014.04.003.

LNN Business Feasibility Project. 2016. Final Report. Birmingham: University of Birmingham and Cardiff University. http://localnexus.org/wp-content/uploads/2018/03/LNN -BUSINESS-FEASIBILITY-PROJECT-FINAL-REPORT-151116-FINALv2.pdf.

Mahalik, Nitaigour P., and Arun N. Nambiar. 2010. "Trends in Food Packaging and Manufacturing Systems and Technology." Trends in Food Science \& Technology 21 (3): 117-28. https://doi.org/10.1016/j.tifs.2009.12.006.

Manzini, Riccardo, and Riccardo Accorsi. 2013. "The New Conceptual Framework for Food Supply Chain Assessment." Journal of Food Engineering 115 (2): 251-63. http://dx.doi.org/10.1016/j.jfoodeng.2012.10.026.

Montreuil, Benoit, Jean-Marc Frayret, and Sophie D'Amours. 2000. "Strategic Framework for Networked Manufacturing." Computers in Industry 42 (2-3): 299-317. https://doi.org/10.1016/S0166-3615(99)00078-0.

Moreno, Mariale, Christopher Turner, Ashutosh Tiwari, Windo Hutabarat, Fiona Charnley, Debora Widjaja, and Luigi Mondini. 2017. "Re-distributed Manufacturing to Achieve a Circular Economy: A Case Study Utilizing IDEF0 Modeling." Procedia CIRP 63: 68691. http://dx.doi.org/10.1016/j.procir.2017.03.322.

Notarnicola, Bruno, Giuseppe Tassielli, Pietro Alexander Renzulli, Valentina Castellani, and S. Sala. 2017. "Environmental Impacts of Food Consumption in Europe." Journal of Cleaner Production 140: 753-65. http://dx.doi.org/10.1016/j.jclepro.2016.06.080.

O'Reilly, Seamus, Anita Kumar, and Frederic Adam. 2015. "The Role of Hierarchical Production Planning in Food Manufacturing SMEs." International Journal of Operations \& Production Management $35 \quad$ (10): 1362-85. https://doi.org/10.1108/IJOPM-04-2014-0157.

Rahimifard, Shahin, Elliot Woolley, D. Patrick Webb, Guillermo Garcia-Garcia, Jamie Stone, Aicha Jellil, Pedro Gimenez-Escalante, Sandeep Jagtap, and Hana Trollman. 2017. "Forging New Frontiers in Sustainable Food Manufacturing." International Conference on Sustainable Design and Manufacturing 2017: 13-24. https://doi.org/10.1007/978-3-319-57078-5_2. 
Rauch, Erwin, Patrick Dallasega, and Dominik T. Matt. 2016. "Sustainable Production in Emerging Markets Through Distributed Manufacturing Systems (DMS)." Journal of Cleaner Production 135 (1): 127-38. http://dx.doi.org/10.1016/j.jclepro.2016.06.106.

Sundbo, Jon. 2016. "Food Scenarios 2025: Drivers of Change between Global and Regional." Futures 83: 75-87. http://dx.doi.org/10.1016/j.futures.2016.03.003.

Trienekens, Jacques H., P. M. Wognum, Adrie J. M. Beulens, and Jack G. A. J. van der Vorst. 2012. "Transparency in Complex Dynamic Food Supply Chains." Advanced Engineering Informatics 26 (1): 55-65. http://dx.doi.org/10.1016/j.aei.2011.07.007.

Valin, Hugo, Ronald D. Sands, Dominique van der Mensbrugghe, Gerald C. Nelson, Helal Ahammad, Elodie Blanc, Benjamin Bodirsky, Shinichiro Fujimori, Tomoko Hasegawa, Petr Havlik, Edwina Heyhoe, Page Kyle, Daniel Mason-D’Croz, Sergey Paltsev, Susanne Rolinski, Andrzej Tabeau, Hans van Meijl, Martin von Lampe, and Dirk Willenbockel. 2014. "The Future of Food Demand: Understanding Differences in Global Economic Models.” Agricultural Economics 45 (1): 51-67. http://doi.org/10.1111/agec.12089.

Wenchao, Wu, Jin Shaosheng, and Tokunaga Suminori. 2016. "Testing Localization of Chinese Food Industries: Evidence from Microgeographic Data." Review of Urban and Regional Development Studies 28 (3): 202-17. http://doi.org/10.1111/rurd.12055.

\section{ABOUT THE AUTHORS}

Pedro Gimenez-Escalante: Research Assistant, Centre for Sustainable Manufacturing and Recycling Technologies SMART, Loughborough University, Loughborough, Leicestershire, United Kingdom.

Shahin Rahimifard: Professor of Sustainable Engineering, Centre for Sustainable Manufacturing and Recycling Technologies SMART, Loughborough University, Loughborough, Leicestershire, United Kingdom. 
Food Studies: An Interdisciplinary Journal explores new possibilities for sustainable food production and human nutrition. It provides an interdisciplinary forum for the discussion of agricultural, environmental, nutritional, health, social, economic, and cultural perspectives on food. Articles range from broad theoretical and global policy explorations to detailed studies of specific humanphysiological, nutritional, and social dynamics of food. The journal examines the dimensions of a "new green revolution" that will meet our human needs in a more effective, equitable, and sustainable way in the twentyfirst century.

As well as papers of a traditional scholarly type, this journal invites case studies that take the form of presentations of practice-including documentation of socially engaged practices and exegeses analyzing the effects of those practices.

Food Studies: An Interdisciplinary Journal is a peer-reviewed, scholarly journal. 